\title{
Cancer screening coverage in Poland - from bad to better to the worst during the SARS-CoV-2 pandemic
}

Paweł Koczkodaj ${ }^{1}$, Michał F. Kamiński ${ }^{2}$ Agata Ciuba ${ }^{1,3}$, Joanna Didkowska ${ }^{1}$

\author{
${ }^{1}$ Department of Cancer Epidemiology and Primary Prevention, Maria Sklodowska-Curie \\ National Research Institute of Oncology, Warsaw, Poland \\ ${ }^{2}$ Cancer Prevention Department, Maria Sklodowska-Curie National Research Institute \\ of Oncology, Warsaw, Poland \\ ${ }^{3}$ Department of Social Medicine and Public Health, Doctoral School, Medical \\ University of Warsaw, Warsaw, Poland
}

Submitted: 28 September 2020, Accepted: 13 March 2021

Online publication: 8 April 2021

Arch Med Sci 2021; 17 (4): 1132-1133

DOI: https://doi.org/10.5114/aoms/134239

Copyright $\odot 2021$ Termedia \& Banach

While a vast majority of countries put much more effort into the fight against the SARS-CoV-2 virus, crucial changes connected with the current epidemiological situation have appeared in other important public health areas - including in cancer prevention. Long term effects of suspended screening may have far-reaching health consequences.

Maringe et al. [1] warned that in the UK a significant increase in cancer deaths due to delays in screening is expected. Despite distinct differences between the UK and Polish health care systems, we can also assume a similar scenario in the case of Poland. Since the start of the COVID-19 pandemic in Poland - the beginning of March 2020 - a visible decrease in screening coverage in Poland has been observed, similarly to almost every country. At the beginning, lockdown in Poland was characterized by a significant limitation of planned medical procedures performed across the country, including cancer screening. Apart from that, on March $20^{\text {th }} 2020$, the Polish government officially introduced in the whole country a state of epidemic, which was combined with e.g. transformation of selected medical entities into specialized facilities dedicated solely for COVID-19 diagnosis and treatment. Moreover, the Polish authorities also decided to introduce restrictions concerning movement of people which enhanced the effect of lowering participation in screening programs as well [2].

In general, the described decrease is continuing also after the end of the national lockdown in May/June 2020 (Figure 1) [3, 4]. In the case of Poland the discussed drop was particularly visible in the case of colorectal cancer screening - which may be connected with use of a specific, more invasive medical procedure - colonoscopy (in comparison with cytology and mammography). Even though in July, August and September 2020 an increase in participation rates was visible, the differences in pre-pandemic and pandemic periods are the biggest in the case of colonoscopy.

The coronavirus pandemic has distorted the basic value of cancer screening - early detection and prevention. To avoid disastrous health, economical, and social consequences, immediate health policy actions are needed, especially as the estimates presented in Maringe et al.'s article may be higher for Polish patients due to multiplication of the pandemic effect and the baseline low screening coverage, which was considered as low or very low before.

\author{
Corresponding author: \\ Paweł Koczkodaj PhD \\ Maria Sklodowska-Curie \\ National Research \\ Institute of Oncology \\ Warsaw, Poland \\ E-mail: pawel.koczkodaj@ \\ gmail.com
}




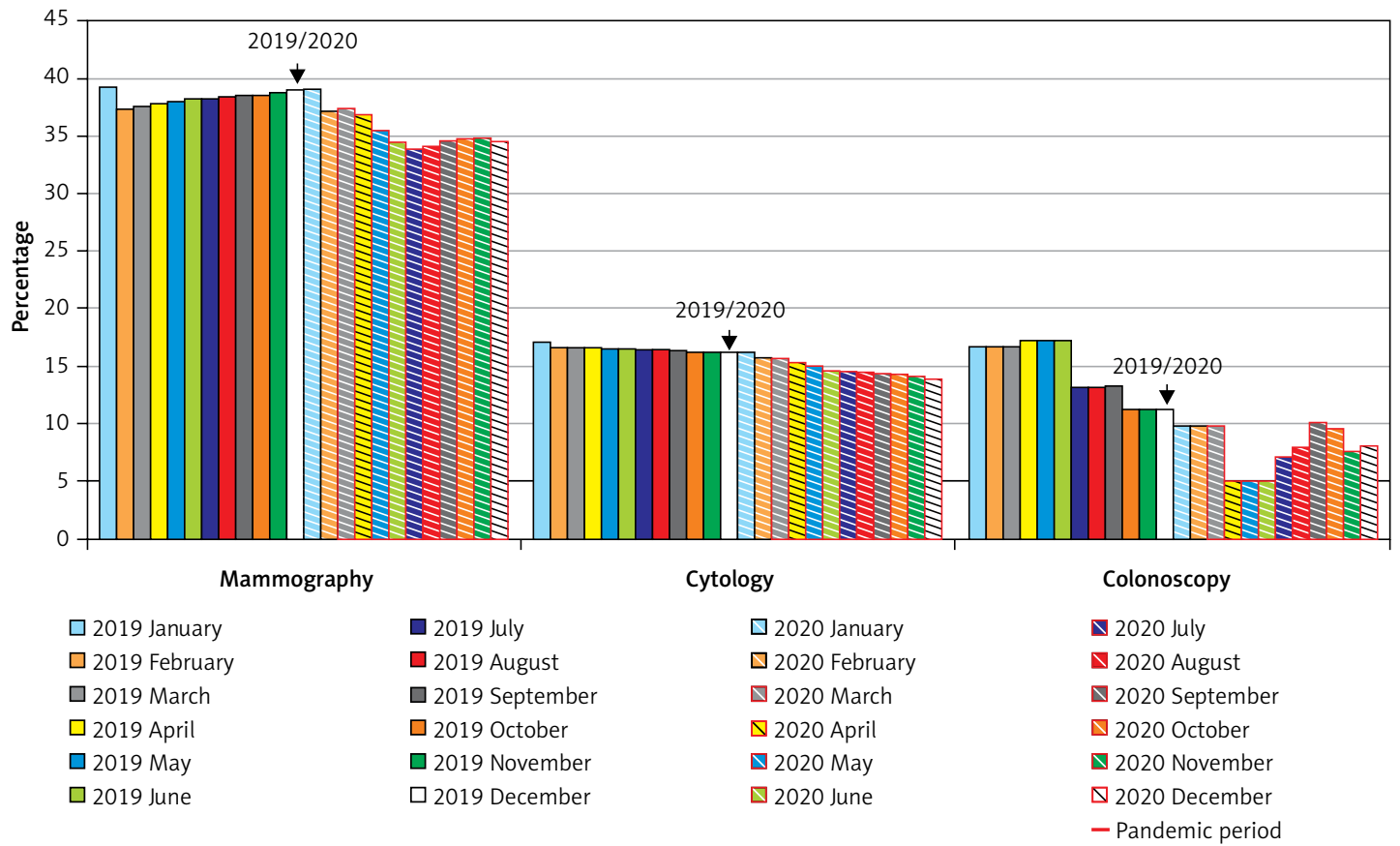

Figure 1. Cancer screening in Poland in 2019 and 2020 (mammography, cytology - coverage rate; colonoscopy participation rate) $[3,4]$

One of the key unanswered questions to guide these health policy actions is to estimate the risk of SARS-CoV-2 virus transmission and COVID-19 disease associated with participation in cancer screening programs - especially in the face of the next - already $3^{\text {rd }}$ - wave of the pandemic.

\section{Acknowledgments}

This work was further supported by the Maria Sklodowska-Curie National Research Institute of Oncology subsidy from the Ministry of Science and Higher Education.

\section{Conflict of interest}

The authors declare no conflict of interest.

\section{References}

1. Maringe C, Spicer J, Morris M, et al. The impact of the COVID-19 pandemic on cancer deaths due to delays in diagnosis in England, UK: a national, population-based, modelling study. Lancet Oncol 2020; 21: 1023-34.

2. Official website of the Polish government - https:// www.gov.pl/web/koronawirus/wprowadzamy-stan-epidemii-w-polsce accessed on March 10th 2021.

3. Data sourced from the National Health Fund in Poland, https://www.nfz.gov.pl/dla-pacjenta/programy-profilaktyczne/dane-o-realizacji-programow/ accessed on February 3rd 2021,

4. Data sourced from the Colorectal cancer population screening program in Poland (on demand) supervised by the Maria Sklodowska-Curie National Research Institute of Oncology in Warsaw, Poland. 